\title{
NED CITY CAMPUS RESTORATION SETTING BENCHMARKS FOR CONSERVATION PRACTICES
}

\author{
Anila Naeem* \\ Sahibzada Farooq Ahmad Rafeeqi**
}

\begin{abstract}
NED University of Engineering and Technology originated in 1922 from what is now known as its 'City Campus' or 'Old Campus' located in the hub of Karachi's historic areas. Shifting of university campus to its present location on University Road in 1975 led to the abandonment of this historic site for more than twenty years; adversely affecting the structures due to neglect and disuse. In 1997 NED City Campus was declared as a listed heritage of Karachi given protection under the Sindh Cultural Heritage Preservation Act 1994. In 2000, realizing its importance as an invaluable asset the NED university's Department of Architecture and Planning conceptualized the vision for restoring this campus and putting it to use; not only on grounds of its historic significance but also for reasons of sustainability, environmental enhancement and regeneration of historic fabric.
\end{abstract}

Restoration of NED City Campus is envisioned with an approach of minimal interventions and respect to the original setting, layout and materials of construction; closely following the international principles of heritage conservation. The approach is to achieve optimum utilization of campus premises primarily as an educational hub; but additionally introducing a variety of ancillary activities to facilitate extended usage of the property. Being an extensive undertaking the project is planned and being executed in phases; the first major phase being the restoration of 'Bai Puribai Becharbhai and Bercharbhai Raichand Block'. This paper gives an overview of this first phase, with a focus on interventions carried out to consolidate the existing structural members of the historic building.

\section{INTRODUCTION TO THE INSTITUTION AND THE CAMPUS}

Being the first educational institution of Pakistan producing local engineering graduates since 1922, N.E.D. University of Engineering and Technology initially started off as the "Prince of Wales Engineering College". In 1924 the institution was renamed (after Nadirshah Eduljee Dinshaw) as N.E.D. Engineering College and became affiliated with the University of Bombay. In 1947 the administration was taken over by

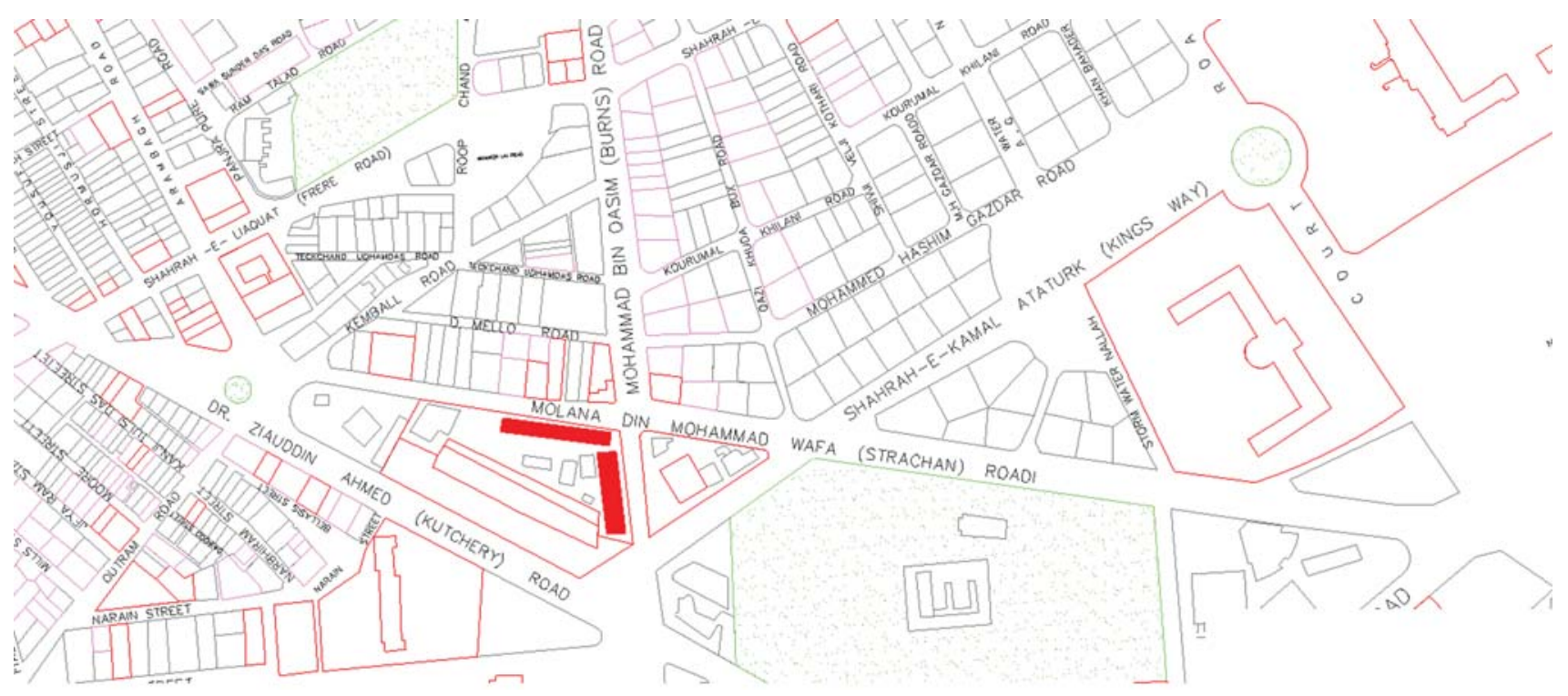

Figure-1: Location Map of NED City Campus.

* Dr. Anila Naeem, Professor, Department of Architecture and Planning, NED University of Engineering and Technology, Karachi.

** Dr. Sahibzada Farooq Ahmad Rafeeqi, Professor, Department of Civil Engineering, NED University of Engineering and Technology, Karachi. 
the University of Sindh and later in 1951 by the University of Karachi. N.E.D. finally achieved the status of a university in 1977; by this time all its academic activities were shifted from the university's original campus located at the junction of Maulana Din Mohammad Wafai (Strachan) Road and Mohammad Bin Qasim (Burnes) Road [Figure-1), to its present location.

\subsection{The Campus and its Buildings}

NED City Campus is a 1.67 acres trapezoidal plot, having several building blocks added to the site at different stages of its history [Figure-2]. Of these the two main historic structures built in yellow Gizri stone align along the two main roads; whereas four other smaller structures built in $\mathrm{RCC}$ are located in the inner core of the plot. Other than these structures of a more permanent nature, there were few shed-like constructions which were dismantled to clear up the site for required additional spaces planned to be built in the later phases of the project. The historic structures of the campus have a very modest architectural vocabulary; however a tall chimney at the junction of Mohammad Bin Qasim Road and Din Mohammad Wafai Road, is an imposing feature of the site that serves as a landmark for the area.

\section{BACKGROUND TO THE RESTORATION PROJECT}

NED City Campus being left abandoned and neglected for almost twenty years left a toll on its old structures, which underwent extensive deterioration. Realizing the campus's historic significance the university administrative decided to initiate an intensive restoration of the buildings and rehabilitate the entire campus again for educational activities. In the light of underlying, internationally accepted principles of conservation, particularly the Venice Charter (1964) and the Burra Charter (1999), the following general restoration guidelines were derived for the City Campus.

- Change in original layout to be kept to a minimum and to be allowed only if considered extremely necessary.

- All repairs in historic structures to be done with original

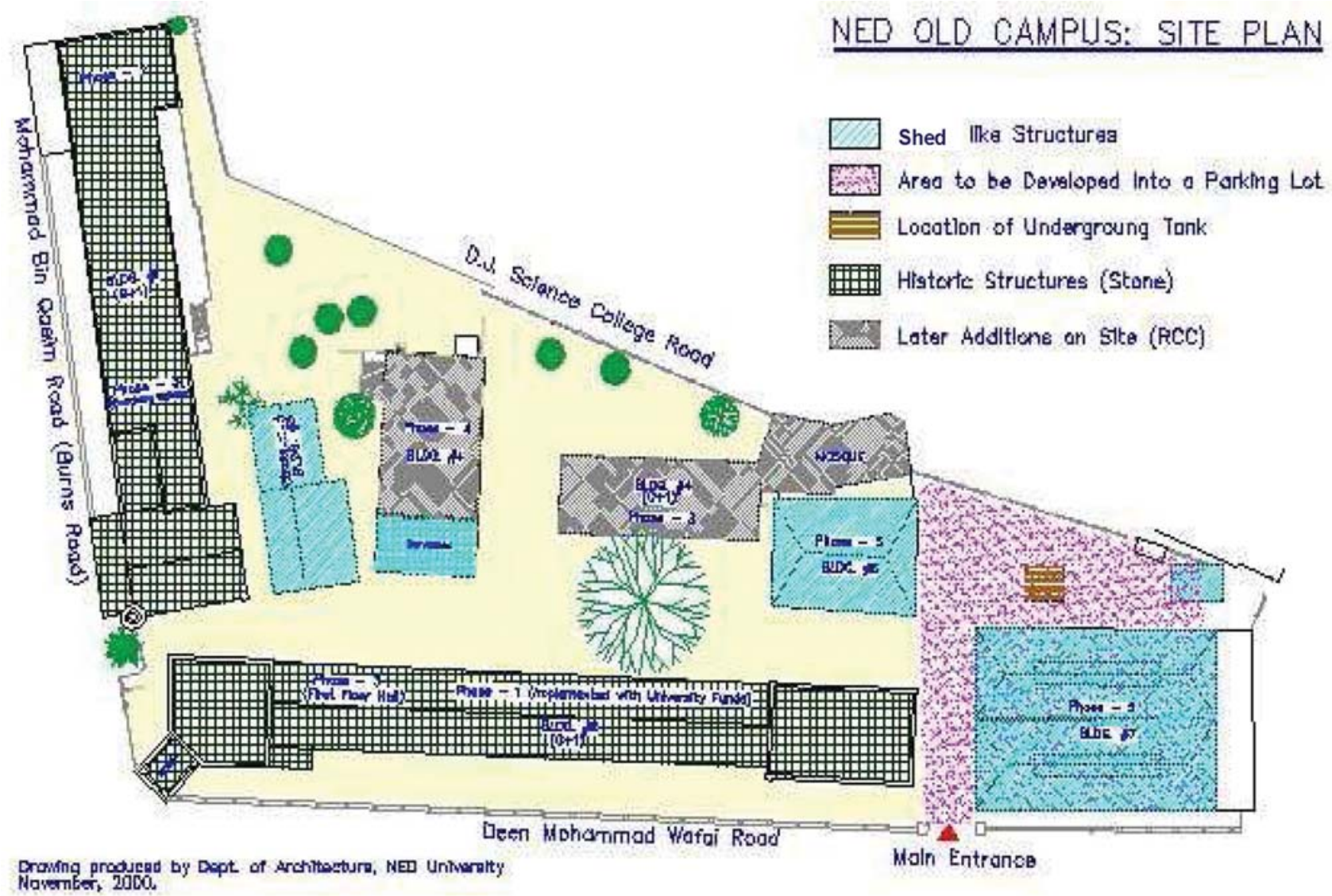

Figure-2: The site as documented before restoration interventions. 
materials and techniques.

- Additions/changes in historic structures to be reversible and clearly identifiable; designed with sensitivity towards original layout and character of space.

- All later period additions on the lot to be considered as part of its historic development (however, those of a non-permanent nature with no architectural or historic significance and negatively impacting the historic fabric to be removed/ dismantled).

The overall site interventions give importance to existing architectural details; replicated for places where these have disintegrated due to lack of maintenance over the years. The areas between buildings are planned to be landscaped to create a micro climate that not only enhances the environment but also allows energy efficiency; allowing outdoor sitting spaces for the students and other visitors to relax and meditate. The guiding principle to be followed for selection of any new plantation introduced on site is to choose species that would help create vistas and frames for heritage structures, rather than blocking them and damaging them by voluminous growth. Among general interventions proposed for stone buildings; the most important is cleaning of stone façade, planed to be undertaken through a scientific method of internationally accepted standard, thus an opportunity to develop appropriate cleaning methods for historic stone façades, in the local context without damaging their original materials (unlike the general practice as prevailing in Pakistan).

Since start of 2005 academic session this historic premises has been exclusively taken over by architecture department and renamed as 'NED Department of Architecture and Planning Campus' (DAP-NEDUET).

The main objectives behind this restoration initiative are;

- To ensure that the campus is maintained as an architectural heritage site and historically significant landmark of the city.

- To ensure that NED City Campus is once again revitalized as an educational hub and properly utilized to its full potential.

- To undertake the restoration project as an exemplary exercise that could serve as a role model for similar projects in the city.

In addition to these primary objectives, a strong component of the project is "research and training" for which the worksite has provided opportunities of learning and hands-on experimentation, primarily for the entire team of professionals involved, and additionally for architecture students present on campus.

The proposed use of the campus after its restoration as the Department of Architecture and Planning has helped in retaining the original spirit of usage as a campus for professional education activity. However, the discipline of architecture being different from other engineering disciplines has resulted in incorporating some changes, but these are minimal. The large hall-like rooms in the original layout are efficiently converted into studio spaces; as their quality of space appropriately fits to studio requirements.

\section{RESTORATION INTERVENTIONS}

In view of funding limitations the project is envisaged with phase-wise development; priority in the first phase given to address immediate academic requirements for architecture students and faculty. Thus areas having severe structural damages (building \#1 and \#5) because of which they could not be put to use were taken up on priority basis. With completion of the first phase of project ample space is now available on campus to comfortably accommodate the routine activities of the department. The future phases are envisaged to further upgrade the campus standards and provide facilities for extra-curricular and research activities initiated within the department.

\subsection{Restoration of Bai Puribai Becharbhai and Bercharbhai Raichand Block}

Architect \& Conservation Consultant: Anila Naeem

Structural Consultants: Mushtaq \& Bilal

Contractor: Beton Construction Company

Year: March 2006 - April 2009

A major component of first phase works is the restoration of Bai Puribai Becharbhai and Bercharbhai Raichand Block (Building \#1), which was in a severe state of deterioration, thus not in usable condition. Lack of maintenance due to abandonment, stretching over a long period of time had caused severe damages to the RCC structural members. The primary cause of deterioration was water penetration inside the building causing corrosion leading to serviceability issues and strength degradation of reinforcement and damage of other building materials. Restoration of this block included major structural repairs, re-doing damaged internal finishes including flooring and lime-plaster, repair and cleaning of all timber elements, restoration of defaced and disintegrated features, and provision of new elements required for proper functioning of introduced activities. The processes followed for major restoration interventions are briefly explained here. 


\subsubsection{Structural Works including consolidation of existing beams - columns and recasting of RCC slabs.}

The most challenging intervention involved restoration and enhancement of the lost strength, stiffness and ductility of deteriorated structural members for the reasons already discussed in the above sections. A workable repair strategy can only be designed if causes and effects of involved deterioration process are well established. Compatibility of repair material with the existing material is also vital for durable repair. A careful investigation was undertaken for each component of the structural system and a well-designed repair strategy was then applied after establishing the desired choice of strengthening. The slabs in all cases were completely demolished and re-cast. The steps sequentially followed include; temporary strutting of beams followed by careful demolition of slabs using manual labor, and then measures for re-strengthening and re-casting structural members [Figure-3(a-f)]. Once the site was cleared of all debris the damaged base of all columns was re-strengthened by first extending their footing and then jacketing of columns with added reinforcement. The damaged portions of beams were then treated; first chiseling out the damaged concrete cover and then treating the reinforcement with anti-corrosion paints and finally applying the repair plasters using bonding admixtures and strengthening fibers mixed with cement and sand. After re-strengthening of the columns and beams the slabs were cast; and the mid-lofts designed using steel were added to increase floor area and achieve optimum utilization of voluminous ceiling heights. The structural repairs were followed by repairs of interior finishes. Giving due importance to original materials the damaged lime plaster of internal wall surfaces was re-placed with plaster of similar composition as that of original and in-situ c.c. flooring to recreate the effect of original flooring.
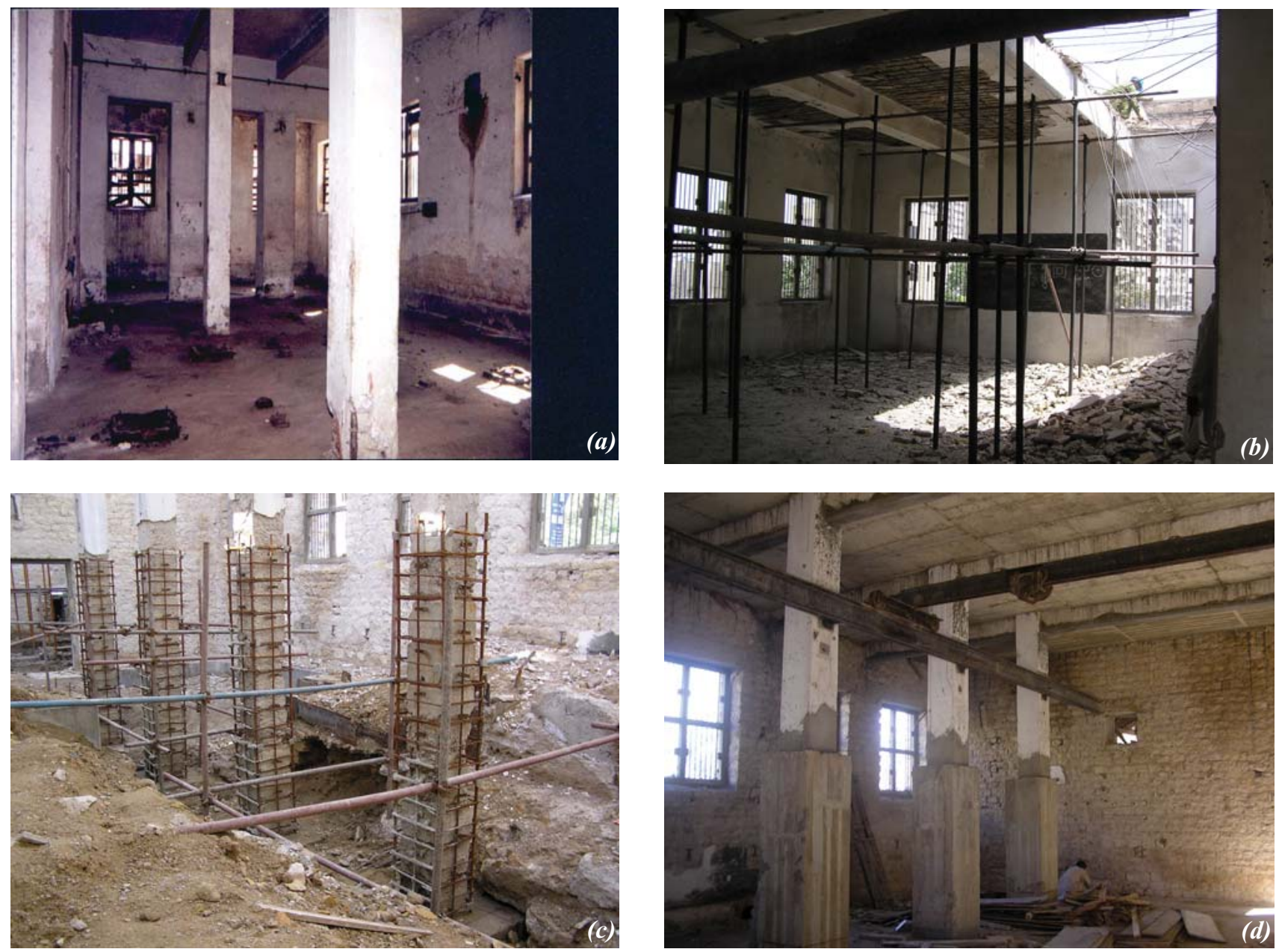

Figure-3(a-d): The restoration process cycle; (a) Deteriorated bases of the RCC column. (b) Temporary propping for relief of loads and chipping/ surface preparation of beams. (c) Reinforcement details for strengthening of lower half of columns. (d) The columns after jacketing; at curing stage. 

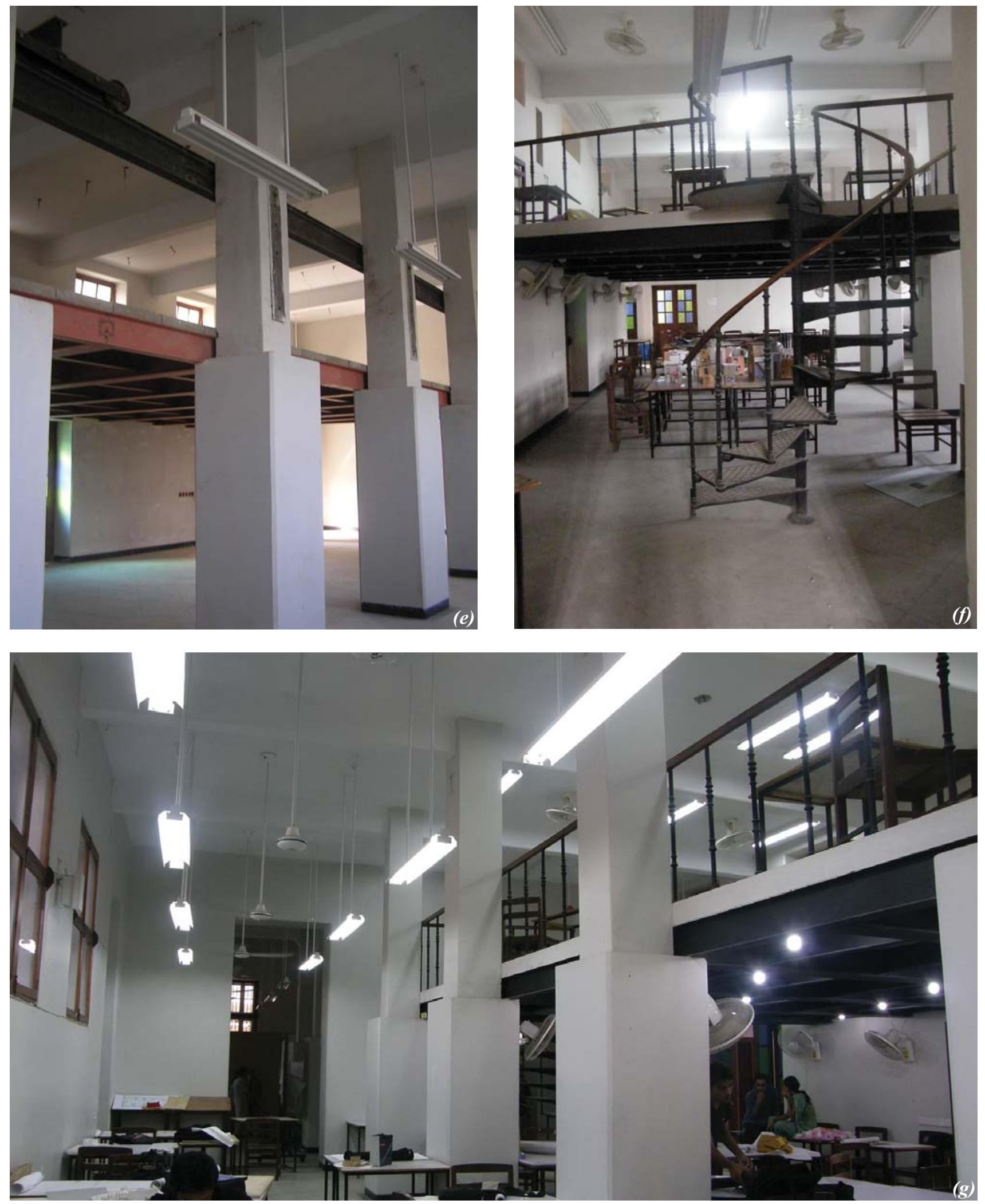

Figure-3(e-g): (e) Repaired columns with mid-loft. (f \& g) View of the space after completion. 


\subsubsection{Re-plastering of interior surfaces with lime plaster}

The original lime plaster inside the building had been badly damaged due to seepage of rain water from window/ ventilator openings and roof slab. The extent of damage made it necessary to re-place it with new plaster. On removal of plaster layer cavities in masonry wall were also discovered. These were filled with lime mortar grouting before application of the new plaster. Lime plaster was prepared on site;
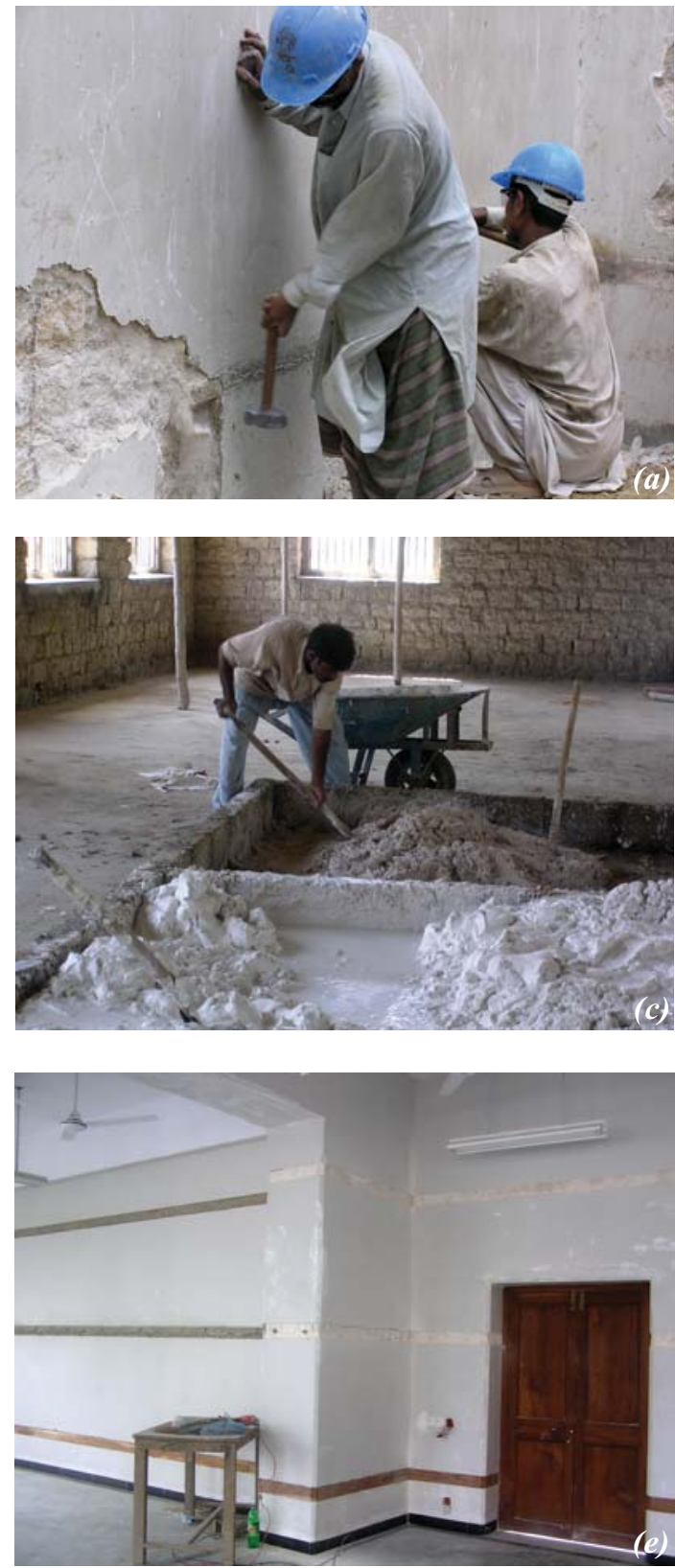

Figure-4(a-f): Lime plaster of stone masonry walls. (a) Removal of existing damaged lime-plaster. (b) Stone masonry walls as exposed after complete removal of existing plaster. (c) Making lime-plaster. (d) Applying the new lime-plaster. (e) Masonry walls before complete finishing of plaster surfaces. (f) Masonry walls after complete finishing of plaster surfaces. following all the steps employed in traditional practice: dissolving the quick lime lumps in water, draining the dissolved liquid through wire mesh into pits dug in ground for slaking of lime - and left for two to three weeks, mixing the slaked lime with jute, sand and crush of lime stone for preparation of lime mortar and grouting, and finally application of lime plaster in two layers [Figure-4(a-f)]. Identification of an expert craftsman to deal with this specialized task took several months and trials to accomplish.
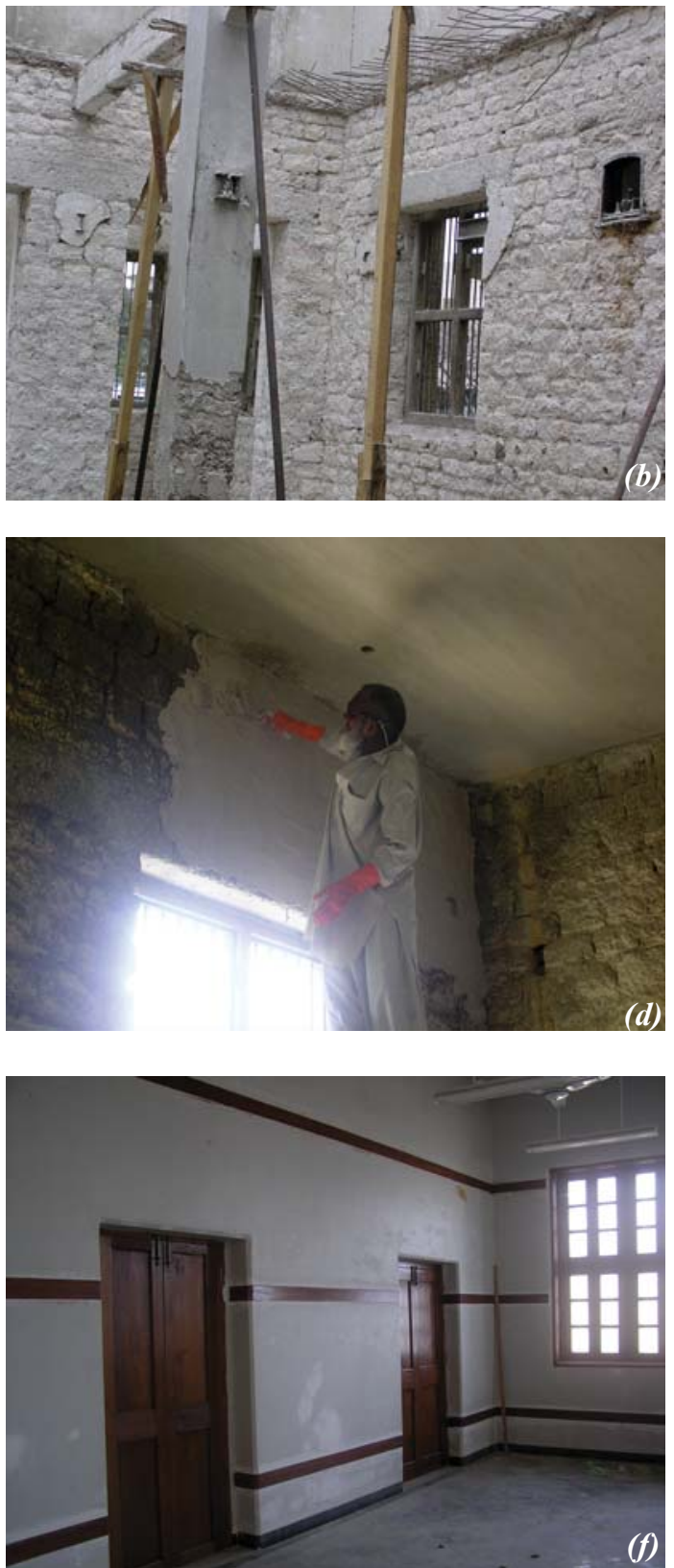


\subsubsection{Cleaning and repair of timber doors/windows}

All timber elements in the building were in a state of disrepair and damage, requiring specialized restoration procedure. For this purpose all door, window and ventilator shutters were dismantled, and tagged with numeric identification corresponding to their location [Figure-5(a)]. The accumulated paint layers were then cleaned following a three stepped process; applying a solution of caustic soda diluted in water with a brush on all surfaces to soften paint, then scrapping off the paint layers manually with metal scrappers, and finally smoothing of surfaces with fine sand paper [Figure5(b-c)]. The original timber texture was enhanced with (matt) clear varnish applied in several coats till desired finish was achieved [Figure-5(d-e)].
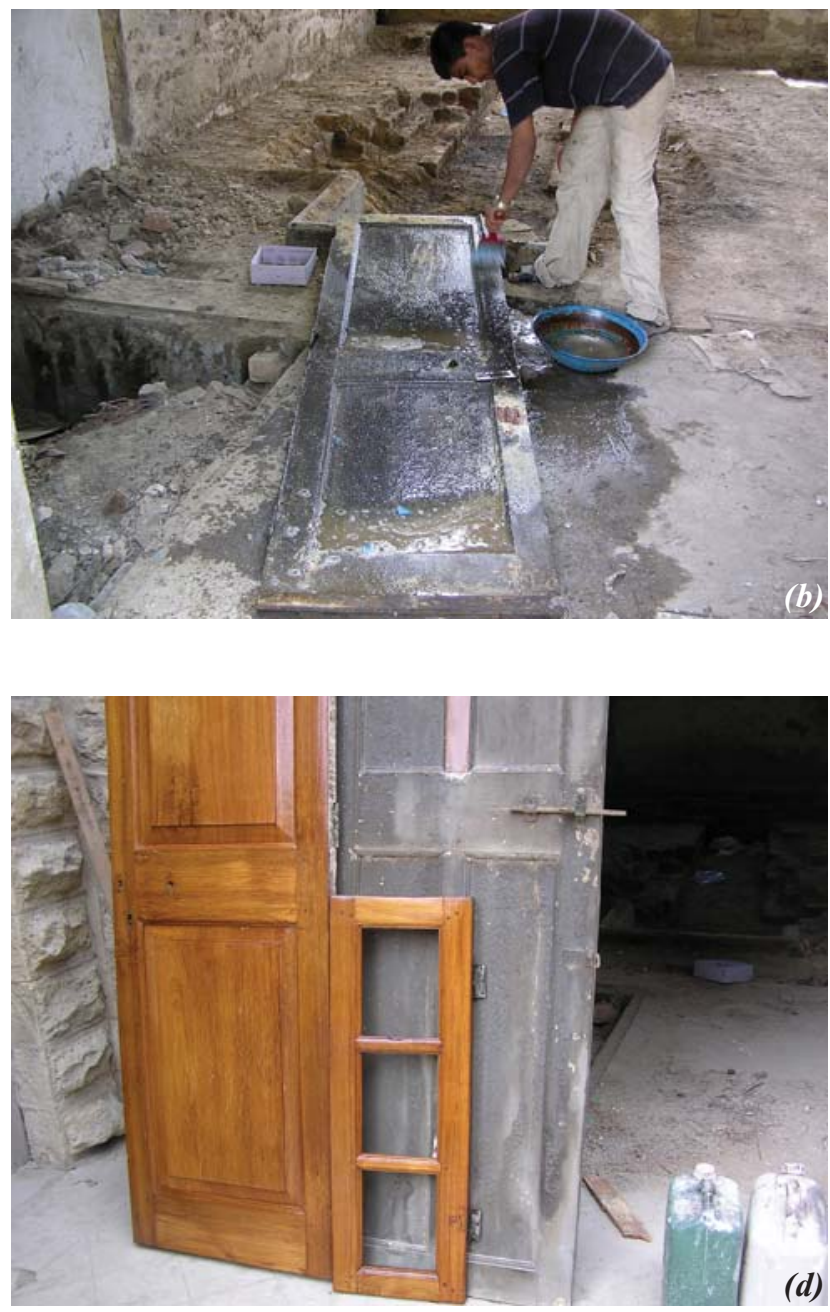

Figure-5(a-e): Cleaning and polishing of timber works. (a) Tagging and numbering of door/ window shutters. (b) Application of solution to soften existing paint layers. (c) Scrapping of paint layers and smoothing of timber surfaces. (d) Polished finish of cleaned timber elements. (e) Final finished door panel.
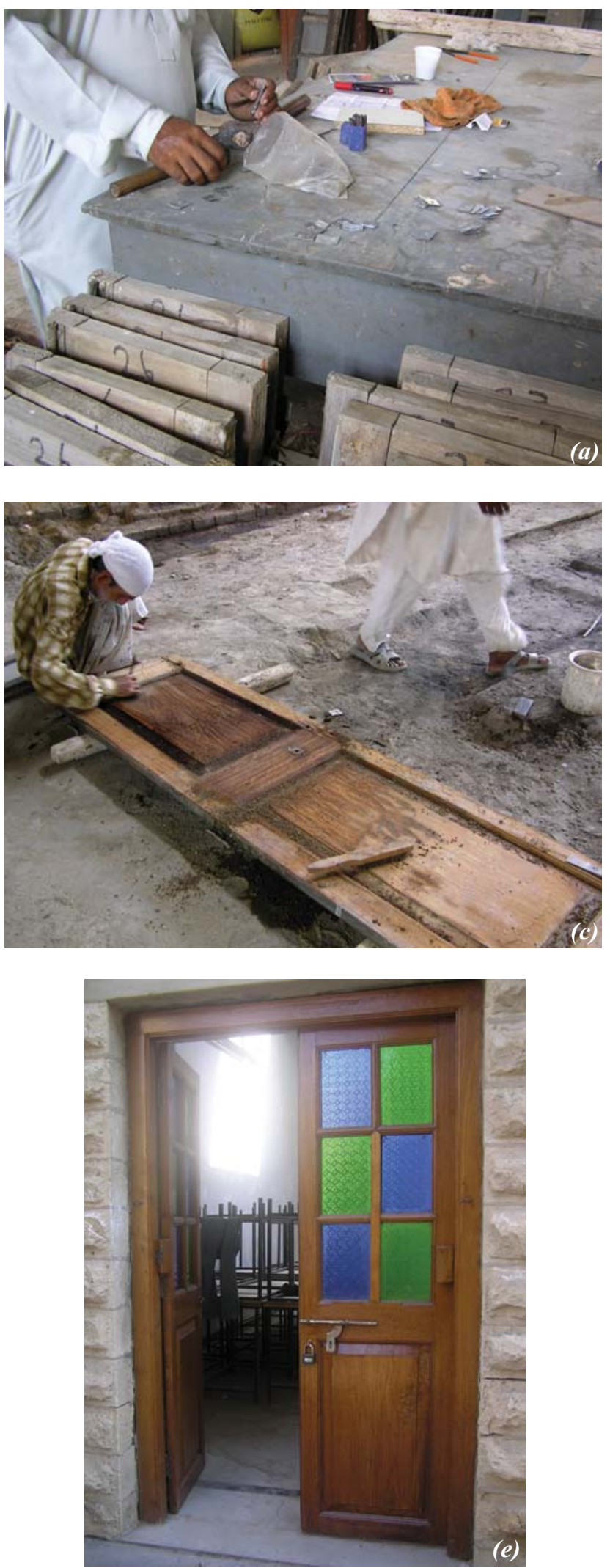


\subsubsection{Liberation of entrance portal and construction of new staircase}

The modest architectural language employed in design of this historic stone structure makes use of few enhancing architectural features; entrance portal being one of these had a high degree of importance, thus had to be liberated from the later additions that defaced it completely [Figure-6(ad)]. The external staircase (already being in a precarious condition) and masonry walls embedding the entrance portal were demolished to carve out the entrance portal. The stone surfaces of portal columns were cleaned of all paint layers and damaged cornices were repaired. The restored entrance portal now forms part of the terrace space that opens out from first floor studios [Figure-6(e)]. As a safety measure a new parapet of simple design was introduced around the terrace. A new staircase bearing a contemporary mark was
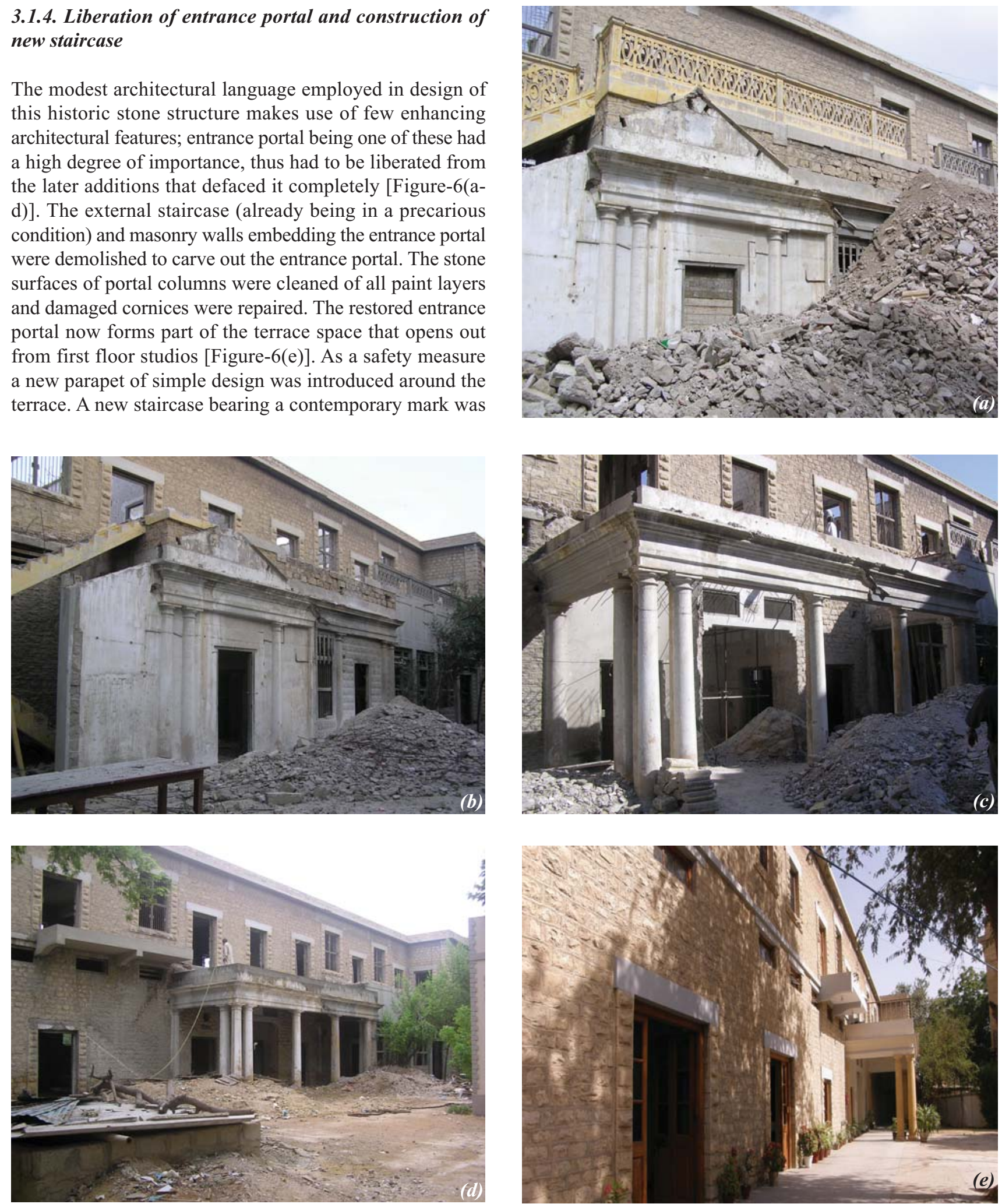

Figure-6(a-e): The entrance portal in building \#1. (a) Entrance portal embedded inside later additions. (b) Removal of later additions. (c) The carved out entrance portal. (d) At the stages of repairs and re-cast slab. (e) The restored entrance portal at completion of works. 
introduced inside the building. These new interventions are clearly identifiable as later additions.

The restoration of Baipuribhai Becharbhai Block was partially funded by a grant from the National Fund for Cultural Heritage and inaugurated on $17^{\text {th }}$ April 2009 by the Governor of Sindh. The building presently accommodates four studios for undergraduate architecture students, and one studio for M. Arch students. In addition there are two smaller rooms being used as offices. The pitched roof space adjacent to the chimney reserved for 'NED Gallery of Historic Archives and Souvenir Shop' is the only space in this block that still awaits restoration works due to lack of available funds.

\subsection{Other Interventions and Further Phases}

Besides major restorations undertaken for Bai Puribai Becharbhai and Bercharbhai Raichand Block, there were a number of other works that required urgent attention; the restoration of timber pitched roof in Seth Fatehchand
Khilwani Block (building \#2) [Figure-7(a-e)], boundary wall on all three sides of the plot [Figure-8(a-b)], restoration of shed for tuck shop [Figure-9(a-b)], construction of new toilet blocks and the structural repairs in building \#5. These works were accomplished as part of the first phase of the project. The second phase of the project includes construction of additional spaces for an auditorium, model-making/ carpentry workshops, materials laboratory, administrative/ faculty offices, basement parking, landscaping of outdoor spaces between buildings for use as sitting areas by students/ visitors and complete restoration of building\#2. Interior works for exhibition hall, NED gallery, reference library and a few other spaces are also required to be taken up in the future. Proper cleaning and treatment of all stone façades using scientific methods is also planned, but could not be taken up due to funding constraints. A specific timeline for completion of the entire campus restoration cannot be envisaged as the implementation of proposed works is dependent on availability of funds; for which ongoing efforts on part of the administration are continuing.
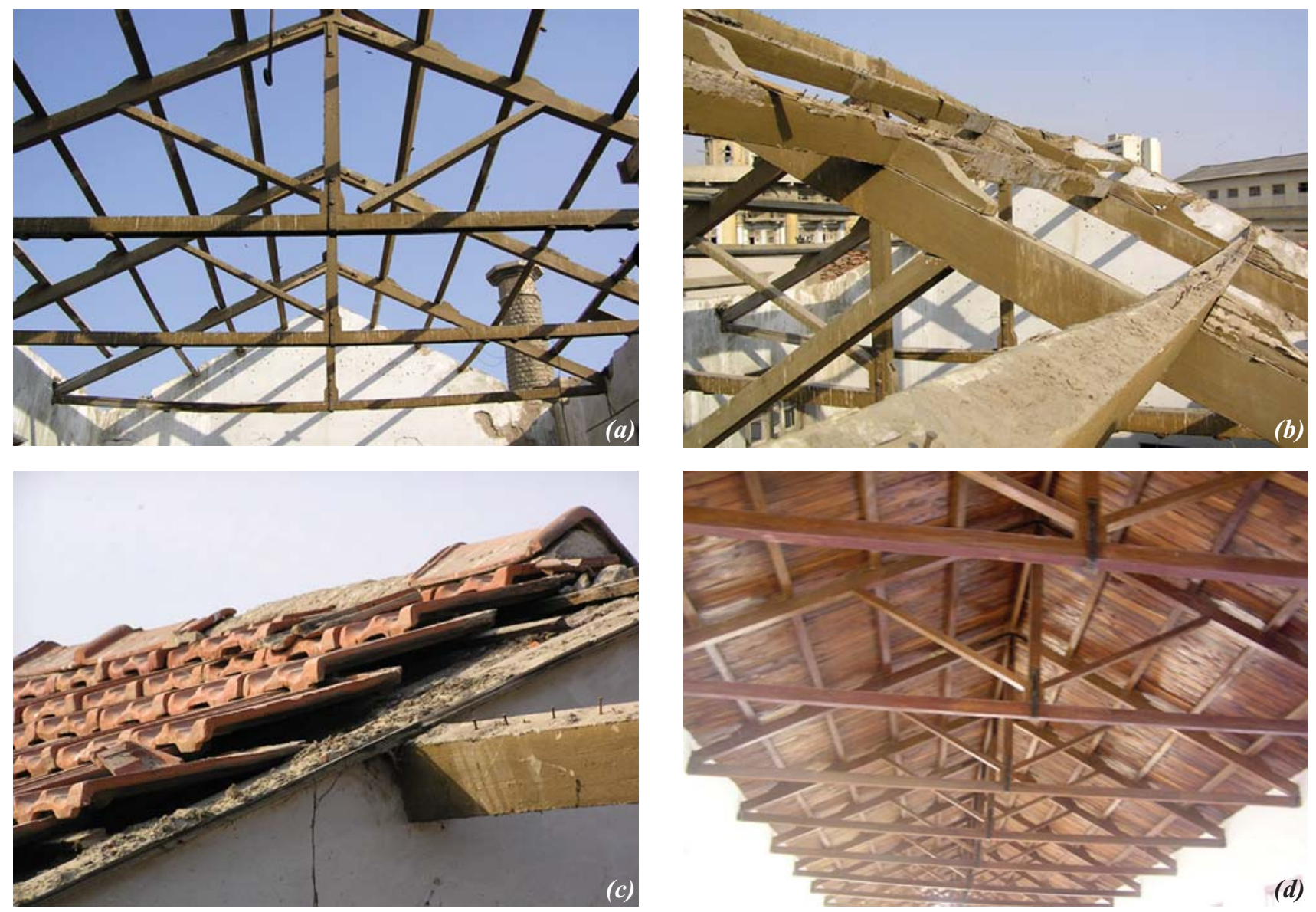

Journal of Research in Architecture and Planning: Vol. 12, 2012 (First Issue) - Architecture, Urban Design \& Planning 


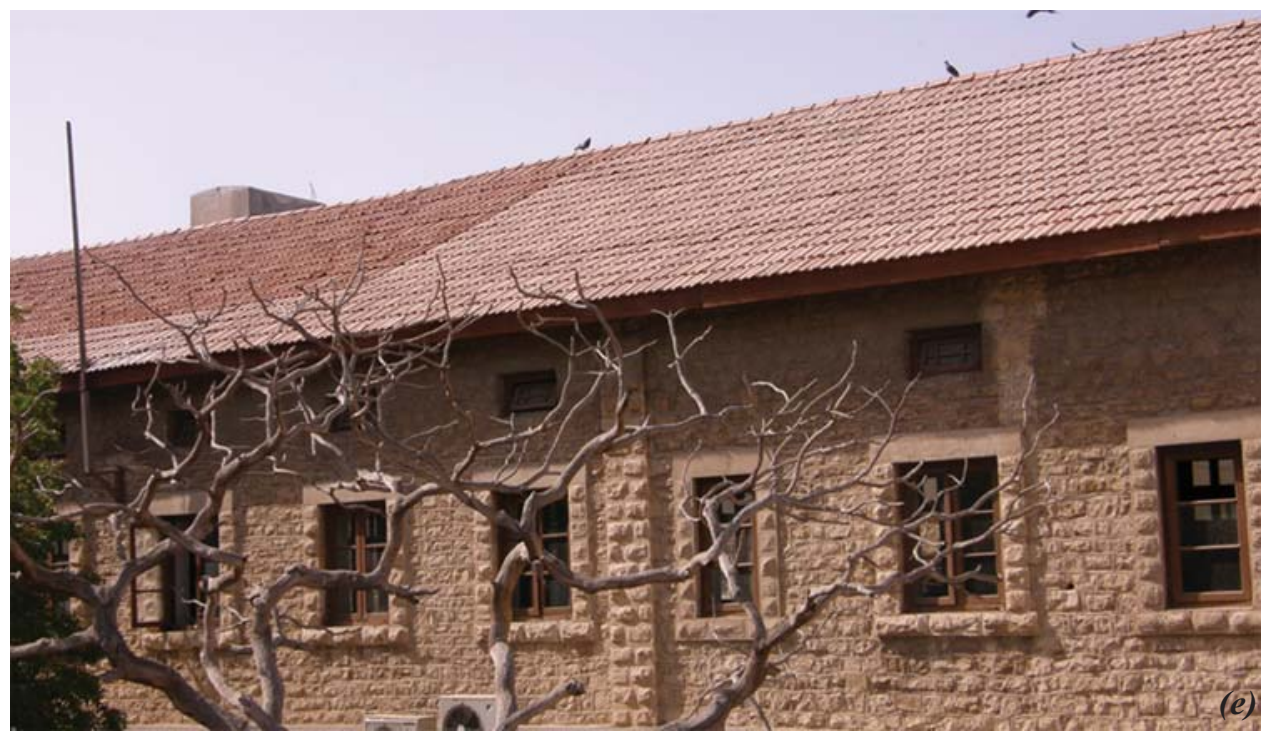

Figure-7(a-e): The original timber pitched roof spanning over a large hall on first floor of Seth Fatehchand Khilwani Block (building \#2) was in a highly dilapidated condition with most of its purlins infected with termite. Only the completely destroyed timber was replaced whereas all the original trusses were cleaned and treated with protective timber coating. The terracotta tiles were also re-used; only the damaged ones being replaced. Since the complete restoration of this space as an 'exhibition and display hall' is still on hold due to lack of funds it is becoming more and more difficult to keep the restored roof in a maintained condition.
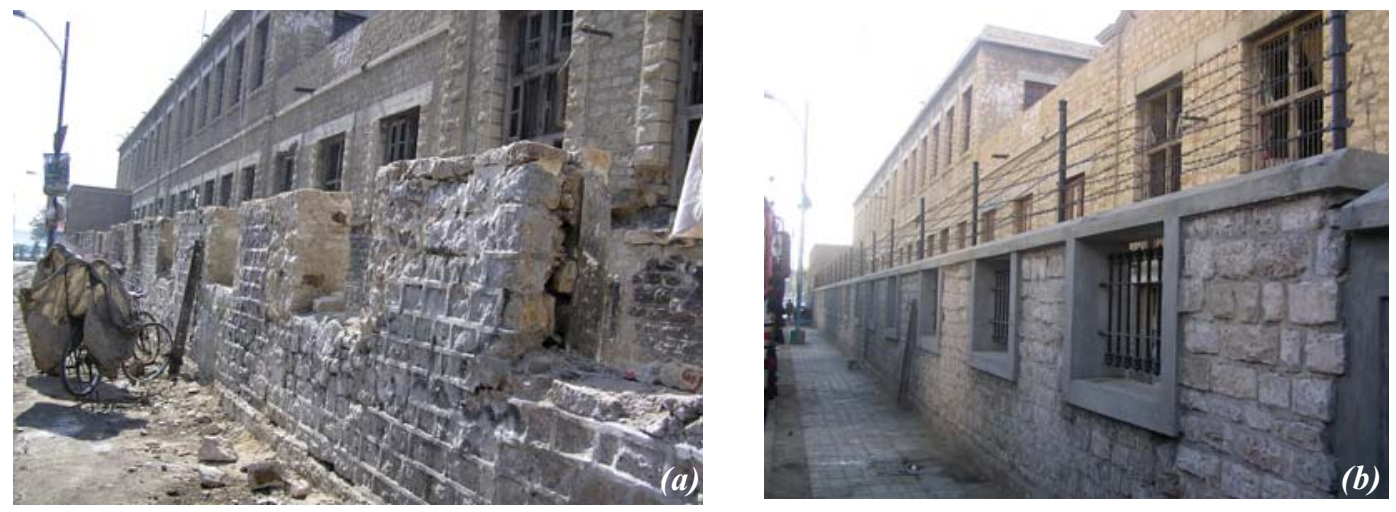

Figure-8(a-b): Restoration works along the Burns Road boundary wall involved demolition of RCC slabs built along the space between the building and the wall. These spaces had been in disuse for many years and became a hideout for drug edicts; a menace now removed from the vicinity due to clearing of area and restoration of the wall.
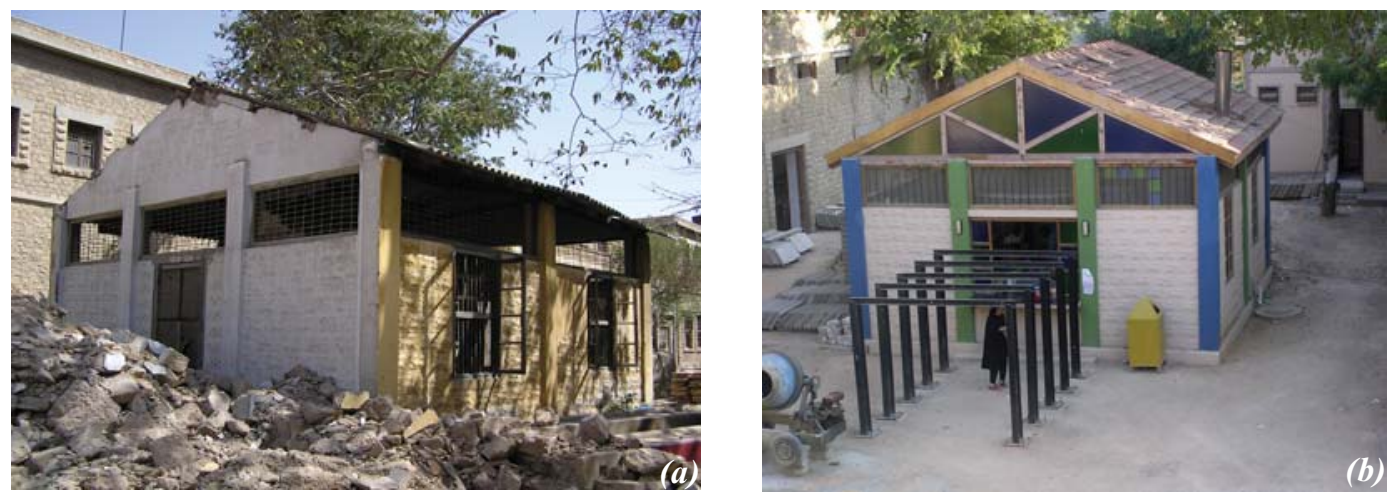

Figure-9(a-b): A small shed restored to serve as a tuck shop. The open spaces around this structure are planned to be properly paved and landscaped for use as outdoor sitting areas. 

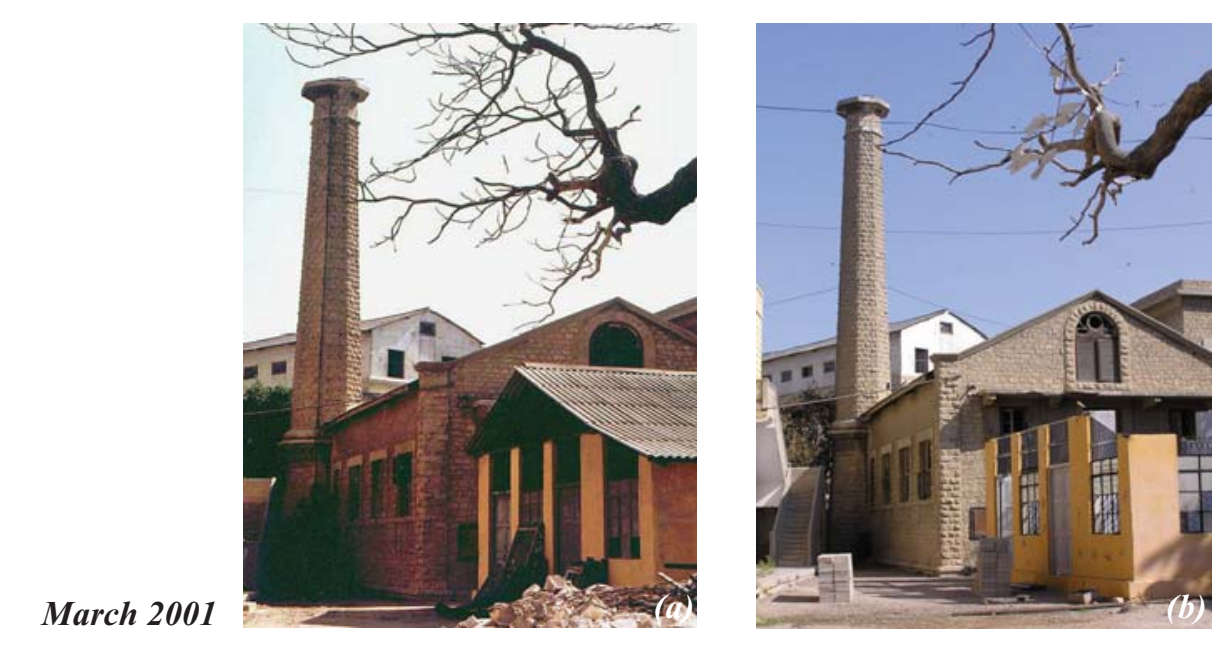

December 2004

November 2005
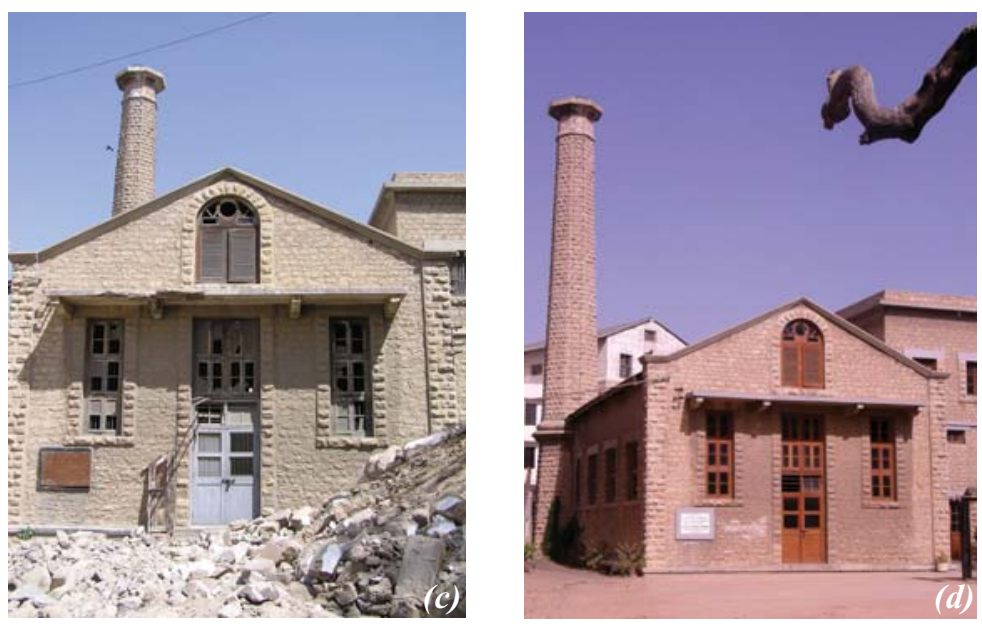

April 2010

Figure-10(a-d): The pitched roof and chimney room in Baipuribhai and Becharbhai Block; the only space in this block awaiting complete restoration and interior works to house the proposed 'NED Gallery of Historic Archives and Souvenir Shop'.

\section{SUMMARY OF PROJECT ACHIEVEMENTS AND OUTCOMES}

The restoration of NED City Campus buildings and putting the abandoned campus to purposeful use has not only ensured the survival of these historic structures into the future but on an environmental level the revival of academic activities on the premises has injected an impetus contributing towards rejuvenation of the historic neighborhood. Prior to its restoration, as an abandoned site the campus had become a hideout for drug addicts. This menace for adjoining residential neighborhood is now eradicated to a great extent by the efforts of a twenty four hour vigilant security service of the university posted at city campus.

For students of architecture, being placed in a heritage site, inculcates a sense of pride; additionally giving them an ideal opportunity to experience and be exposed to the real life issues of our inner city crisis. Bearing close affinity to the historic areas of the city helps develop an association and build connectivity with much that is being taught in relation to our built environments. Being placed within the city center however, brings with it challenges of infrastructure constraints and limitations; addressed at management level. These include dealing with long power break downs, shortage of water supply, flooding during monsoon rains due to backflow from choked drains, threats of graffiti and vandalism, etc. Over the years the university administration has gradually resolved some of these challenges by experimenting with alternate arrangements; solutions for remaining hurdles are constantly being sought.

The actual restoration processes and the adopted scientific approach created an opportunity to experiment and develop methods for restoration of various historic materials and revival of traditional techniques. From lime plaster to cleaning 
of timber, in-situ cement flooring, strengthening of structural concrete, waterproofing of khaprail roofing; each task required innovative experimentation to achieve the desired standard. Managing this within the fixed rules of tendering and working with lowest bidder created extraordinary situations, challenges and delays. Credit here needs to be given to the contractor, who being an alumnus of the university did not treat this project as a regular undertaking and overlooked the profit margins to deliver quality work. The on-site experimentation for seeking solutions to various requirements has enriched the experiences of all associated professionally with the project. The results produced in the first phase now provide a standard benchmark to follow in future phases of the project.

\section{CONCLUSIONS AND FUTURE DIRECTIONS}

Since the projects' inception in 2000, the university and team of professionals involved have struggled to maintain quality standards; from documentation to analysis and developing the restoration proposal, to actual execution of proposed works there have been extensive efforts to overcome challenges posed due to the extraordinary nature of the project. The project can be seen as being placed in an ideal situation; the property owned by initiators of the project, backed by an educational institution that believes in excellence, and the availability of trained conservation professional on board. It probably is among the very few restoration projects in Pakistan where ample time was allowed for sound research and analysis to base restoration decisions; the execution of works is patiently monitored ensuring that lack of funds and pressures for early completion of the project do not result in compromising the merits of the master plan that was carefully developed to maximize on potentials of the campus as an important historic site, located within the hub of the city. The NED City Campus now not only provides a fairly comfortable academic environment to its students but has also helped instigate a positive impetus on an environmental scale, adding charged energies to its degenerating historic neighborhood. Painstaking efforts are being made to carry out the entire project on internationally accepted standards of conservation/ restoration so that it serves as a source of direct learning for future conservation projects, specially undertaken within the challenging circumstances of a public sector organization.

The successful completion of the project's first phase however, remains as its first milestone. Much of what is envisioned in the master plan to achieve optimum utilization of the city campus to its full potential still remains unaccomplished. The completion of the project in accordance to the vision en-framed in its master plan would only be possible if future policies and decision making remains consistent to what has been proposed and approved in the master plan.

\section{Bibliography}

Naeem, A. "NED City Campus Restoration Project Proposal”. Unpublished Report, NED University, Karachi 2001.

'Educational Buildings in India’, Superintendent of Government Printing, India, Calcutta, 1911.

International Charter for the Conservation and Restoration of Monuments and Sites (The Venice Charter) 1964.

The Australia ICOMOS Charter for the Conservation of Places of Cultural Significance (The Burra Charter) 1999. 